\section{"Carne crua e torrada": a experiência do sofrimento de ser queimada em mulheres nordestinas, Brasil}

\author{
"Raw and charred flesh": the experience of burned \\ women in Northeast Brazil
}

\author{
"Carne cruda y tostada": experiencia del \\ sufrimiento en mujeres del nordeste de Brasil al \\ padecer quemaduras
}

\author{
${ }^{1}$ Centro das Ciências da \\ Saúde, Universidade de \\ Fortaleza, Fortaleza, Brasil. \\ 2 Universidade Christus, \\ Fortaleza, Brasil \\ Correspondência \\ C. N. Arruda \\ Programa de Pós-graduação \\ em Saúde Coletiva, Centro \\ das Ciências da Saúde. \\ Universidade de Fortaleza. \\ Rua República do Líbano \\ 533, Fortaleza, $C E$ \\ 60160-140, Brasil. \\ cristianiarruda@hotmail. \\ com
}

\begin{abstract}
In Northeast Brazil, death from burns is a widespread, pervasive threat to poor women. This anthropological study describes the experience of personal suffering among female burn patients. In 2009, six "information-rich" cases were investigated at the Burn Center in Fortaleza, Ceara State, Brazil. Open ethnographic interviews with key informants, narratives of lived experiences, and participant observation at the clinic and patients' home were conducted. The methods included content analysis, systems of signs, meanings, and actions, and contextualized semantic interpretation. The emerging metaphors are embued with the cultural meaning of "monstrosity" and gender violence by fire - inscribed mercilessly in the woman's body. "Accidents" caused by flammable liquids (alcohol) hide the cruel reality of "raw and charred flesh". The scars can disfigure the victims as "non-persons", destroying their moral reputation and leading to social rejection. In the Brazilian Northeast, the social vulnerability caused by sequelae from burns demands a policy for humanized care.
\end{abstract}

Burns; Social Stigma; Social Vulnerability; Anthropology
Cristiani Nobre de Arruda 1 Andrea Stopglia Guedes Braide 1,2 Marilyn Nations 1

\section{Resumo}

No Nordeste brasileiro, a morte por fogo é uma ameaça onipresente e banalizada entre mulheres empobrecidas. Este estudo antropológico descreve a experiência do sofrimento de ser queimada. Em 2009, foram investigados seis casos "ricos em informação" no Centro de Queimados, Fortaleza, Ceará, Brasil. Entrevistas etnográficas abertas com informantes-chave, narrativas de experiências vividas e observação participante na clínica e no domicílio foram realizadas. Utilizamos os métodos Análise de Conteúdo, Sistemas de Signos, Significados e Ações e Interpretação Semântica Contextualizada. Revelou-se que as metáforas emergentes são carregadas de significância cultural da "monstruosidade" e da violência de gênero pelo fogo - inscrita impiedosamente no corpo feminino. $O$ "acidente por combustivel" (álcool) esconde a cruel realidade de "carne crua e torrada". A cicatriz é capaz de desfigurá-las em "não-pessoas", maculando sua reputação moral e gerando a rejeição social. No Nordeste brasileiro, a vulnerabilidade social provocada pela sequela da queimadura exige uma política de humanização do cuidado.

Queimaduras; Estigma Social; Vulnerabilidade Social; Antropologia 


\section{Introdução}

Em 5 de junho de 2013, num lance de extrema crueldade, um grupo de criminosos ateou fogo na dentista Cinthya Magaly Moutinho, que morreu queimada em seu consultório, em São Paulo, Brasil 1. De fato, somente no ano de 2010, 4.297 mulheres brasileiras foram vítimas de homicídios, ou seja, 4,4 homicídios para cada 100 mil mulheres 2. Estima-se que, em 2013, 4.717 homicídios ocorreram entre mulheres brasileiras 2 . O brutal assassinato da dentista queimada viva, em seu próprio consultório, repercutiu nos noticiários com imagens fortes, revoltando telespectadores estarrecidos. Poucas cenas de nações em guerra ou que passam por convulsão social chocaram tanto e abateram os cidadãos brasileiros como essa barbárie na grande e "civilizada" metrópole do Sudeste do país.

No Nordeste brasileiro, acrescente-se, a morte por fogo é uma ameaça onipresente e até banalizada na realidade cotidiana entre mulheres empobrecidas, discriminadas, esquecidas e repudiadas pela sociedade ${ }^{3}$. Com um sistema social fortemente patriarcal, em que as relações assimétricas ${ }^{4}$, o machismo ${ }^{5}$ e a violência de gênero ${ }^{6}$ estão enraizados e inscritos no panorama sociocultural, essas mulheres enfrentam agressividades diariamente. No Ceará, a taxa de homicídios de mulheres, em 2010, foi de 3,7 2 para cada 100 mil mulheres, 165 foram assassinadas 2 , a maioria por seus parceiros 7; dados que sinalizam outra gritante injustiça. Embora com um viés de banalidade, uma circunstância em que o valor intrínseco da vítima, nesse caso, é menosprezado pelas autoridades e pela sociedade como um todo ${ }^{8}$.

O tratamento de queimaduras é um desafio complexo ${ }^{9}$, pois esse universo permanece esquecido das políticas públicas e dos debates acadêmicos. A causa de "acidente por combustível” (álcool) no perfil epidemiológico esconde a crueldade cotidiana vivida por essas mulheres anônimas, queimadas de forma tão traumatizante ${ }^{8}$. As vítimas são rotuladas como "não pessoas" 10 , sofrem caladas (entre quatro paredes) sem o frenesi midiático. Ainda, no Ceará, seres humanos aniquilados socialmente por doenças infecciosas carregam marcas e cicatrizes da iniquidade socioeconômica, a realidade injusta, inscrita no corpo, silenciada e pouco estudada nos aspectos subjetivos 11. Fora das estatísticas nacionais e longe dos noticiários, a queimadura simboliza o estigma humano 11,12 da experiência de ser queimada viva. Sobrevivendo na pobreza e na exclusão social, a voz e os gritos da mulher nordestina são, frequentemente, silenciados pelo medo da violência de gênero 6,8,13. Cicatrizes desfigurantes da queimadura estigmatizam-nas como a escória da sociedade 10 , iguais às paquistanesas, vítimas de queimaduras por ácido pelos maridos raivosos 14. A história das mulheres cearenses, paupérrimas, queimadas vivas, precisa ser contada.

Em seu trabalho Deep China: The Moral Life of the Person, Kleinman et al. 10 advertem que desvelar a violência cotidiana entre os que mais sofrem é um grande desafio para o pesquisador, pois viver na pobreza extrema já implica uma violência estrutural subjacente e fora do foco dos gestores públicos. O fio condutor que orienta este artigo reside na compreensão do sofrimento dessa mulher. Não buscamos descrever a queimadura como problema biomédico, o que reforçaria somente sua dimensão patológica, mas, sim, como experiência sociocultural 15. Assim, narrando os acontecimentos que as vitimaram consegue-se, por meio de uma triste analogia, remeter às manifestações profanas, culturais e religiosas que são a marca mais intensa do processo de ter sido queimada.

Indagamos, portanto, como é ser mulher vivendo em uma pobreza esmagadora e sentir seu corpo queimando? O que está em jogo quando sua imagem é brutalmente deformada diante do olhar de outros? Como os profissionais de saúde percebem o trauma desse sofrimento? Diante desses questionamentos, objetivamos compreender e descrever a experiência do sofrimento de ser queimada das mulheres nordestinas.

\section{Metodologia}

\section{Um cenário socialmente vulnerável}

No período de janeiro a outubro de 2009, esta pesquisa, com abordagem antropológica, foi realizada numa unidade especializada de queimadura, em hospital municipal público, na capital de Fortaleza, Ceará, Nordeste do Brasil (população estimada do Ceará em 2013 - 8.778.576) (Instituto de Pesquisa e Estratégia Econômica do Ceará. Anuário Estatístico do Ceará 2010. http:// www.ipece.ce.gov.br, acessado em 03/Fev/2014). Nesse período, foram atendidos 2.459 pacientes, 1.386 mulheres $(56,4 \%)$ foram tratadas por queimaduras. O Centro de Tratamento de Queimados (CTQ) é totalmente diferente de tudo que se conhece em hospital - o limite entre a vida e a morte é parceiro muito próximo nessa unidade. Um CTQ está impregnado de visões, pele rasgando do corpo, odores, dor intensa. Os pacientes ficam frequentemente isolados, com pouca ou nenhuma mobilidade e, muitas vezes, são submetidos à observação do sofrimento de outros pacientes. O 
CTQ está situado no contexto social propício para investigar as interfaces da pobreza, a violência de gênero e as queimaduras.

No cenário brasileiro, queimadura é um problema social, o crescimento da injúria acompanha o aumento populacional 16 . O percentual aumenta considerando que algumas formas de trauma e doenças são restritas a certos grupos demográficos (DATASUS. http://www.datasus.gov.br/da tasus/datasus.php, acessado em 28/Out/2010). Para efeito de comparação, hoje, são cerca de 15,7 milhões de pessoas vivendo na pobreza no Brasil, dos quais, 6,53 milhões continuam abaixo da linha de pobreza 17. É nesse contexto que as pessoas pobres constituem um grupo vulnerável para queimaduras, devido às condições ambientais desfavoráveis 16 , e que empobrecem ainda mais como consequência da lesão18. Ninguém acredita que os brasileiros sejam materialmente mais "inflamáveis" que os cidadãos de países ricos, pois $95 \%$ das queimaduras relacionadas ao fogo ocorrem em países de baixa e média renda, incluindo o Brasil 18. Os dados causam espanto; mas, de acordo com a Organização Mundial da Saúde (OMS), as queimaduras vão ultrapassar as doenças infecciosas como a primeira causa de morte no planeta, em 202018.

Na cidade de Fortaleza, região de grande apelo turístico, impera a desigualdade econômica e a segregação social 19. Nessa cidade, é gritante a separação entre a cidade dos ricos e a periferia de miséria. Não por acaso, essa cidade, por seu cenário de contrastes, foi apontada, no mês de outubro de 2012, como a 5 a cidade mais desigual do mundo 20 . Nesse cenário, a pobreza revelase mais persistente, precisamente entre as mulheres 2,13,17. A discriminação de gênero, além de acentuar a pobreza, contribui significativamente para desvalorizar o papel da mulher na sociedade 2,13 . A violência, aqui, atua como um potencializador dessa desigualdade 2,6,13,17.

Essa violência social aparece nas narrativas das mulheres que são vítimas de processos de exclusão de diferentes ordens, sendo devastadas e tendo seu sofrimento ignorado no Nordeste brasileiro.

\section{Desvelando as marcas corporais}

Entre os métodos qualitativos 21, os dados foram coletados por meio de entrevistas etnográficas 22 abertas com informantes-chave, narrativas de experiências 23 vividas de ser mulher e queimada e observação participante 24 . Identificamos, junto à enfermeira chefe, "seis casos ricos em informação" 25 para aprofundar, com faixa etária $\geq 18$ anos, registrados e tratados na unidade com grande queimadura e que receberam alta, mas que continuam em tratamento ambulatorial. A média de idade das informantes foi de $32,0 \pm 24,5$ anos. Na maioria, casadas, do lar e pobres; todas residem em bairros de periferia.

A entrevista etnográfica não requer a elaboração de um roteiro fechado 22 ; ela parte de perguntas disparadoras: "Como você se queimou? $O$ que realmente importa para vocês? O que está em jogo diante das marcas corporais? Onde estão as opções para melhorar estas cicatrizes? Há mesmo opções?". Em momento oportuno, as informantes foram incentivadas a narrar livremente todo o percurso do trauma da queimadura; as dificuldades vivenciadas e as expectativas em relação às marcas corporais. Narrar na sua voz permitiu às informantes expressar a visão êmica 26 da sua história, os acontecimentos e experiências pessoais, como é prevista na narrativa. A narrativa é uma técnica utilizada na antropologia médica como meio de acesso à reconstrução da experiência da doença. A investigação narrativa permite ao informante desenvolver uma história longa, que seja objetiva, mas com liberdade para mencionar detalhes de acordo com sua experiência ${ }^{23}$.

As pesquisadoras imergiram no cenário social da pobreza. De fato, enriquecemos, validamos e contextualizamos as falas com observação participante 24 do tipo livre. A abordagem antropológica permitiu acumular informações dentro do leque de atores envolvidos no domínio do ambiente 27 ao serem observados, no decorrer do tratamento: centro cirúrgico, consultas médicas, atividades mensais do grupo terapêutico encenadas pelos diferentes agentes institucionais (pacientes, cirurgiões, enfermeiros, assistente social, fisioterapeuta, terapeuta ocupacional e psicólogo), visitas domiciliares, encontros sociais com familiares e vizinhos, anotando-as no diário de campo.

Os dados qualitativos foram interpretados por meio do método de análise de conteúdo temática de Bardin 28. Após leituras repetidas das transcrições, emergiram temáticas como: a experiência do sofrimento, o sofrimento social e as deformidades físicas, as marcas e as cicatrizes corporais, a violência e a autoestima, a monstruosidade, a relação paciente e profissional, as práticas de cuidado e a cura. Inspiramo-nos na “Interpretação Semântica Contextualizada" de Bibeau \& Corin 29, que interliga a experiência individual de pessoas, aqui as mulheres queimadas, aos "Sistemas de Significados e Ações" 29 que elas atribuem e as reações tomadas, ou não, diante das cicatrizes corporais. Assim, desvelamos as cicatrizes no corpo, seus significados e sua forma de agir. Apesar da difícil tarefa, compreendemos o sofrimento na íntegra, inserindo-o no seu mun- 
do moral local e contexto macrossocial 12. Enfim, produzimos uma etnografia como sugere Mol 27, uma praxiografia, um espaço da complexidade ontológica, constituindo uma descrição densa 30 do que era observado acerca do corpo queimado.

Optamos por apresentar as falas com uma escrita que entrelaça a voz das informantes, tendo o cuidado de destacar as expressões que lhes pertencem. A pesquisa, conforme a Resolução no 466/12, do Conselho Nacional de Saúde, foi aprovada pelo Comitê de Ética e Pesquisa do hospital (no 31.956/09). Os nomes das informantes são fictícios.

\section{Resultados}

No hospital público especializado em tratamento de queimaduras em Fortaleza, as mulheres descrevem as repercussões que a queimadura produziu nas suas vidas, atingindo sua pele impiedosamente. Todavia, desvelam os motivos que determinam as causas reais do acidente, como sobrecarga de trabalho, ciúme e violência física. A narrativa dá voz a sofrimento, dor, limitação com a deformação física. Nas entrelinhas dos diálogos com essas mulheres, seus familiares, colegas e profissionais de saúde, surgiram metáforas da aparência corporal carregadas de significância cultural. A cicatriz da queimadura é capaz não só de desfigurá-las, mas também macular sua reputação moral. Ao mesmo tempo, no último caso, oferece uma nova forma de significar o viver. Por fim, inspira a cura "hipodérmica", isto é, a cura da alma no corpo queimado.

\section{O eu-monstro: uma aparência ímpar}

Lúcia, 38 anos, cozinheira, foi internada no CTQ com $40 \%$ do corpo queimado, com queimaduras de 2 o e 3 o graus. Assim, horas antes, uma garrafa de álcool gel próximo ao fogão aceso explodiu, queimando sua face, pescoço, seios, braços e mãos: "Só lembro da dor e do fogo azul subindo pelo meu rosto (...) Gritava muito, corria, me batia todinha pra apagar o fogo! ... Vi minha carne saindo dos meus peitos e da minha mão! Senti o cheiro de carne torrada! Foi horrível!'. Durante 45 dias, sofreu acidose, perda de fluidos, alterações no equilíbrio endócrino, ameaças de infecção e dor intensa: "A dor que sofri foi a pior que já senti como gente!". Em casa diante do espelho, reflete a imagem "monstruosa" de si mesma; de susto, ela olha para os lados e abaixa a cabeça numa atitude de submissão: "Peguei o espelho e, quando me vi, me senti um monstro!" [Choro].

Diante disso, está implicado que a aparência continha tudo. Na visão de Lúcia, a marca corpo- ral traz desajustes desse impacto e que se apresentava de várias formas. Em nossos encontros, chorava, mas conseguia rir; apresenta-se confusa com tudo que está lhe acontecendo: a cicatrização, as limitações, o desfiguramento. Com pele enrugada, manchada e dilatada, parecia deformada e estranha, assustando os olhos de quem a observa. Na verdade, sua aparência incomum mascarava algum horror oculto, com características aberrantes e consequências desastrosas para quem cruzava seu caminho: "Acho que assusto as pessoas (...) Tenho vergonha de sair na rua porque todo mundo me olha! A imagem é coisa séria, as pessoas julgam a gente pela aparência. (...) Perguntam o que eu tenho! Tem gente que tem medo de ficar perto de mim, pensando que tenho aquela doença" [refere-se à hanseníase].

Observamos que a monstruosidade como acepção simbólica do mal é manifestada pela força física desenvolvida por sua própria aparência. Porém, segundo o conjunto de proposições no qual se inscreve, pode adquirir vários significados dentro de alguns contextos, entre eles, temos a "vergonha do corpo".

Com apelo à metáfora do monstro, aludimos ao fato e indagamos o que são monstros? Quem são eles? De modo complementar, percebemos que são perguntas complicadas, e muitas respostas acabam sendo doloridas, chegando perto demais de nossos hábitos e crenças. Desse modo, é mais fácil rejeitar a reflexão e se refugiar na metáfora do monstro: a pele grossa pelo queloide que envolve toda a área queimada, a hipertrofia demarca seu pescoço e face, chamando atenção.

Em geral, notificamos que essa aparência é uma evidência, não é um dado inequívoco, pois não estamos falando aqui de metáforas etéreas, mas, sim, de uma mulher de carne e osso, ao narrar ser isolada do mundo, perdendo dignidade, respeito, capacidade laborativa e desvalorização social perante sua aparência: "Antes de me queimar, era um monstro de trabalhadora, agora sou uma trabalhadora monstra. Nem sei se meu chefe vai querer que volte a trabalhar desse jeito!". Lúcia, ao se reconhecer como monstro, aproxima-se de um sintoma da imperfeição e, ainda, percebe que sua "carne" precisa ser substituída e, além disso, não consegue aceitá-la como ela é e quer corrigi-la. Assim, a informante espera ansiosamente as reparações cirúrgicas, pois o fisiológico está aqui subordinado ao simbólico: "Vim no hospital pra ver se o Doutor tira essa marca do meu corpo! Queria fazer a cirurgia, pra me ver menos monstruosa... Vai melhorar, né?!". Na sala de espera do ambulatório, o médico declara que não é o momento de fazer as reparações cicatriciais: "Volte daqui a um mês, continue fazendo exercício, não pegue sol, use o protetor solar e a malha....". 
Etnografar essas praticalidades, diante de um "corpo múltiplo", envolve vários agentes em ação, pois o tratamento é multidisciplinar. Assim sendo, perguntamos ao médico como está relacionada essa prática assistencial e do cuidado; ele comenta: "O cuidado da queimadura é manter a circulação, prevenir infecção, obter cobertura adequada para a ferida, preservar funcionalidade e reabilitação do segmento envolvido. O período de maturação cicatricial dela não está efetivo. Devemos ter senso para intervir corretamente... A ansiedade é normal, ela ainda não está preparada para fazer a reparação cirúrgica". Enfim, essa é a performance clínica-laboratorial da morbidade das queimaduras.

Nesse sentido, é relevante notar que a incorporação do conhecimento teórico-prático sobre o processo cicatricial como perspectiva auxilia na decisão de intervir ou não no corpo da informante. Na ausência de limites de significação que a tecnologia cirúrgica ainda não oferece, Lúcia procura os limites desse fato. Na realidade, seu intuito é remediar as incertezas do orgânico pela adição de procedimentos técnicos, já que tentava restaurar um equilíbrio perturbado. Assim, ela volta com ressentimento, sobrevém uma decepção imensa contra o corpo marcado pela queimadura, vivenciada como infâmia, uma desgraça, uma experiência imunda percebida como privação e exclusão e como prova de humilhação atroz.

\section{A marca de Marcos}

Final de tarde de domingo, Icaraí, praia cearense, ao encontrar o companheiro, Eva, vendedora, 32 anos, é vítima de tentativa de homicídio pela explosão da garrafa de álcool líquido que ele, ao borrifá-lo sobre o corpo dela, provoca o acidente, causando a ela sérias lesões. O álcool, como aerossol, ficou no ar, formando uma ponte entre a chama e a garrafa, explodindo ao sugar o fogo para dentro dela: "Ele jogou o álcool em mim, depois começou a isqueirar!... Desesperada, falei que não era brincadeira... aí, o isqueiro acende me queimando! Gritei muito. Tentei apagar o fogo com as mãos, por isso, tenho pouco movimento. Engoli fumaça, queimando por dentro. O cheiro de carne queimada era forte! Saí correndo para rua, queimando viva, depois não lembro de nada".

Permaneceu 90 dias internada na unidade de queimados, $35 \%$ do corpo em carne viva, com queimaduras de 2 o e 3 o graus. Avaliação clínica: $60 \%$ de chance de óbito, $40 \%$ de recuperação. Superou infecções severas, desbridamentos. Após dois anos do acidente, a recuperação estética e funcional envolve várias cirurgias: “...passei por dezenas de cirurgias [clínica plástica] para me- lhorar essa marca, tiram pele do meu corpo, nesta última consulta, queriam tirar das minhas costas!... Fiquei preocupada, é o único lugar que não tem marca...!". Ela vislumbra a manifesta preocupação com a aparência diante da marca física de seu corpo, provocada pela atitude de especulação, preconceito e curiosidade do outro: "Minha roupa foi feita pra mostrar as costas, se tirarem carne dela? Tenho que fazer nova roupa pra cobrir... Pedi o médico que tirasse das coxas, resta pedacinhos de carne sem marca... Só porque sou pobre, sabe o que ele [médico] me perguntou? Tá suvinando [poupando] pele mulher?!".

Insegura diante do ato violento e com autoestima abalada, Eva narra acontecimentos especiais e as emoções que esses despertam toda a significação de sua imagem corporal: "Não consigo arranjar trabalho por conta dessas marcas, ainda tenho que cobrir para sair... e ainda ficou o nome dele marcado em mim... Olha bem pra minhas marcas, olha bem!... olhou? Viu! Elas têm o "MA" de Marcos!" (Figura 1).

Marcada pela queimadura, por violência do companheiro, sofrida no lar, Eva traz inscrito no corpo a percepção da enfermidade, fruto cumulativo de sofrimento. Na sua narrativa, a sequela é ligada semanticamente à integridade física. De fato, nos proporciona informação de como os problemas da vida são criados, controlados e têm significados. Consequentemente, eles parecem sem sentido, mas a busca de sua inserção se materializa na sua fala e nos cuidados com seu corpo e pode ser decisivo para ela. Não consegue dirigir mais seu destino nem elaborar projetos de vida, pois são poucas as escolhas e acredita não haver mais oportunidade nem motivação. Essa é a repercussão nas cicatrizes dessa mulher socialmente excluída, vítima de violência e da miséria crônica. Apesar do seu desconforto com a cicatrização, porém, é possível uma adaptabilidade na prática do cuidado. Junto ao cirurgião plástico, argumentarmos uma melhor colaboração ao utilizar seus conhecimentos e tecnologias para reparar o corpo dela, principalmente quanto às possíveis consequências estético-funcionais. Portanto, ele [cirurgião] relata: "Nós médicos enfrentamos problemas relacionados à falta de enxerto para cobrir toda a área lesada, ela é uma grande queimada. Ela não tem outra área corpórea, tem que ser nas costas".

Nesse caso, embora a tomada de decisão seja individual, pedimos ao cirurgião para explicar a Eva que a alternativa cirúrgica, frente às queimaduras extensas e profundas que ocorrera, garantia menor morbidade para área doadora. O procedimento ameniza o problema, porém, não o soluciona. No ambulatório, numa fala esclarecedora, as pesquisadoras informam 


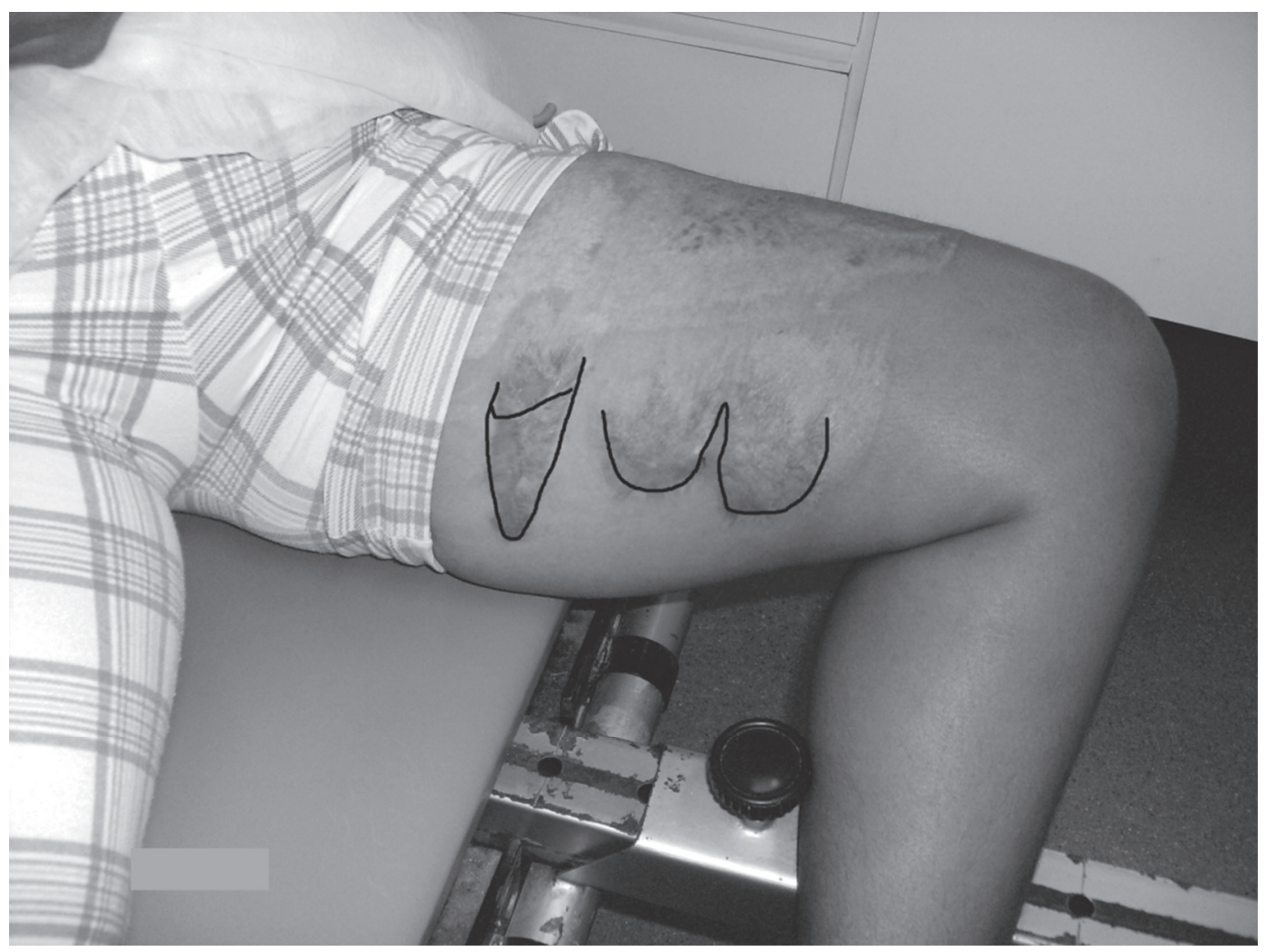

que o tratamento irá fornecer o melhor resultado estético possível. Finalmente, ela aceita, e a acompanhamos ao centro cirúrgico com todos os bisturis e competências inspiradas para um cuidado ativista.

\section{Cura à flor da pele}

Tânia, 24 anos, estudante, sofreu queimaduras junto à irmã mais velha ao brincar com fogo e papel sobre o colchão. A brincadeira acaba tragicamente, sendo narrada por D. Nélia, a mãe: “Era muito fogo...! Peguei água tentando apagar, mas só piorava, aumentando a labareda!". Entre chamas, a mãe salva as crianças: "Entrei desesperada pela labareda, peguei Natália... depois Tânia pelos cabelos!". A proporção do fogo fez a família perder a casa. As crianças adentram no Centro de Tratamento, queimadas por chama direta. Natália teve $50 \%$ do corpo queimado, com queimaduras de 2o e 3o graus. Após vinte dias internada, falece por choque séptico, comenta a mãe: “Foi muita dor... [pausa] quando o médico falou que Natália morreu... Não queria perder Tânia!". No mesmo instante que Natália falece, Tânia sai da UTI, fala sua mãe: "Não sei se ria ou chorava, uma morta, outra saindo de coma... Era dor e alegria!".

Tânia tinha feridas que a colocavam em risco de morte. Eram lesões profundas de 2o e 3 o graus, em $75 \%$ do segmento queimado, atingindo cabeça, face, pescoço, tronco, braços, mãos, genitália, pernas e pés. Os médicos disseram que ela tinha apenas $1 \%$ de chance de sobrevivência. Até parte de seus ossos derreteram. Lutou contra a morte: “Deus e Nossa Senhora deram força pra suportar tanto sofrimento... Minha filha sofreu na carne toda dor!" [D. Nélia]. Em sua voz, Tânia não recorda o acidente, a não ser por um detalhe: "Não lembro de nada, nem da Natália... lembro do pano azul, que minha mãe enrolou, acho que era o manto de Nossa Senhora!".

Sua hospitalização ultrapassa um ano e seis meses, com tratamento longo e exaustivo, apre- 
sentando diversas complicações orgânicas, realizou 41 cirurgias, readmissões para enxertias, reparação da sequela física; como reconstituição de septo nasal, mamas e genitália, prótese ocular esquerda, uso de expansores teciduais no couro cabeludo. Diante disso, batalhando contra todo sofrimento e desejando a cura, a vida ganha significados e perspectivas para Tânia: “...Meu desejo é voltar estudar, entrar na faculdade!".

A narrativa deixa claro que ela tem uma maneira única e irrenunciável de encarar sua adversidade física perante as visões reveladoras em shopping, restaurante e na maior avenida de compras da cidade. Percebemos que, na modernidade, a única extensão do outro é frequentemente a do olhar: "Não me importo com olhares dos outros, sou diferente... Não fico chateada quando perguntam o que aconteceu... Não gosto quando zombam de mim!". A aparência coloca a informante sob o olhar apreciativo do outro e, principalmente, transformando em estigmas, em marcas fatais de imperfeição moral. Ela está submetida ao campo de visibilidade e sabe disso.

Ao mesmo tempo, traz uma característica fundada na sedução e na comunicação com relação ao seu corpo - sua aparência, declarando e encarando sua vida igual às adolescentes ditas normais: "Vou à festa, praia, academia, já namorei! Faço tudo normalmente, sem medo de nada...! Homem olhando pra mim é paquera, mulher é sapatão" [risos]. Enfim, o envolvimento com a família fez com que ela não perdesse toda essa vitalidade: "Minha mãe é responsável pelo meu jeito! Meu pai me deu a vida duas vezes, uma por nascer e outra doando pele!".

Ao longo da pesquisa, ainda no ambulatório, sentimos a curiosidade e, tendo cuidado meticuloso, indagamos se ela desejava realizar a cirurgia reparadora. Ela responde com docilidade, legitimando seu "look" como presença de estilo. Por fim, essa prática foi exposta à avaliação médica, obtendo a seguinte declaração: “...todos os procedimentos realizados em Tânia foram gerenciados da melhor maneira possível, e o melhor de sua aparência foi alcançado". Apesar de extrapolar o limite da corporeidade, chama atenção de que, na vida, manter a esperança, mesmo diante de tantos acontecimentos, mostra que Tânia, na sua essência, é mais forte que a dor e a sequela da queimadura.

\section{Discussão}

A experiência do sofrimento de ser queimada narrada por nossas informantes revela uma especificidade ímpar da mulher cearense; reflete uma intimidade com a violência de gênero ${ }^{6,13}$. As queimaduras trazem preocupações ao universo feminino: aparência física, autoestima, relações conjugais etc. As lentes que sustentam os sintomas que incomodam essas mulheres ao enfrentarem dilemas trágicos e viverem sob tensão são mais intensas do que se possa perceber. Com isso, as lacunas do desconhecimento são preenchidas por narrativas intimistas. Partimos da compreensão dos fenômenos ligados à saúde e à doença, como é proposto por Kleinman ${ }^{15}$, ao esclarecer o processo ao longo da enfermidade, tais como: o sofrimento, a singularidade e a estranheza do fato de sentir-se doente. Compartilhamos com o autor 15 o fato de que enfrentamos uma "illness" grave e complexa, com fisiopatologia, comorbidade e mortalidade 9,17,18 (DATASUS. Morbidade por Queimadura. http://www.datasus.gov.br/da tasus/datasus.php, acessado em 28/Out/2008).

Nosso estudo explora a percepção do corpo queimado dessas mulheres. De fato, o corpo que estudamos, e que adoece, é um corpo integrado no plano do discurso, em que a metamorfose é prevista, produzida e imposta 31 . De modo complementar, o trabalho desenvolvido por Porter \& Vigarello ${ }^{32}$ e Courtine ${ }^{33}$ permite iluminar melhor a compreensão do corpo como objeto cultural de uma totalidade, que envolve: corpo orgânico, de carne e sangue, corpo agente e instrumento de práticas sociais, econômicas e políticas, corpo subjetivo 32,33 .

Em todo o percurso, expandimos esse corpo, enquanto pele 34 que tem valor simbólico: a carnalidade da existência humana. Exprime verdades, legitimando sua incontornável força e singularidade, assinala Anzieu ${ }^{34}$. De um lado, ele é visto como o demarcador das fronteiras entre o indivíduo e o mundo; de outro, é concebido como dissociado do homem 34,35. Sabemos que uma das qualidades adotadas para definir a beleza do corpo humano é o da conservação da pele, pois não se trata mais de uma ingênua apologia da pele/corpo. Ninguém ignora que pele/corpo sustentam a mente, e que a saúde física tem impacto sobre o bem-estar mental 34,35. Concordamos com Anzieu 34 e Montagu 35 que a pele é uma abertura para o mundo, uma memória viva. É um termômetro do gosto pela vida. Ela envolve e incorpora a pessoa, distinguindo-a das demais, encenando a aparência que rege as nossas sociedades. Ou pelo contrário, ela encarcera em uma identidade insuportável da qual desejamos abdicar, tendo, como testemunha, as lesões corporais desencadeadas pelas queimaduras 34,35 .

Nas narrativas de Lúcia e Eva, há "bons argumentos" que derivam caos e vulnerabilidade, pois Anzieu ${ }^{34}$ relata que a relação com o mundo de cada homem é, portanto, uma questão de pele, e de solidez. Não estar bem em sua pele implica, 
algumas vezes, a reorganização de sua superfície para vestir uma nova pele e nela melhor se encontrar 35,36. Indiscutivelmente, isso é igualmente abordado, real ou metaforicamente, quando a pele dessas mulheres desvela as tensões vividas e que as obrigaram a procurar ajuda médica (cirurgia). Constatamos que as informantes queimadas na face, mãos, seios, genitália, por exemplo, manifestam curiosidade sobre sua aparência. Os dados aqui encontrados corroboram os trabalhos que evidenciam alterações na imagem corporal e a identidade quando a queimadura atinge locais do corpo com maior exposição 9,36.

Percebemos, ao entrar na voz das nossas informantes, que a dor da lesão e sua cicatrização, a tensão que permanece na pele, a visão da ferida ou seus traços são uma experiência difícil de esquecer e superar. Ao constatar as alterações corporais produzidas pelas queimaduras, Lúcia e Eva enfrentam sentimentos negativos, como distúrbios da autoimagem. Revelam fissuras profundas no mundo interno, uma cicatriz ${ }^{33}$ do espírito que demanda um reordenamento terrível da experiência cruel do sofrimento. Provoca, muitas vezes, sentimentos de inadequação, rejeição familiar ou conjugal implícita num processo de marginalização social 37 .

As evidências surgidas dos dados deixam claro que, no ambulatório, elas queixam-se da deformidade. Consequentemente, percebemos que o principal motivo, consciente ou inconsciente $35,36,38$, que leva nossas informantes a se operar é a necessidade de melhorar a autoestima, o afeto e a aprovação da sociedade. Diante do aspecto estético, o acompanhamento psicológico é recomendado para minimizar o sofrimento, garantindo a continuidade do tratamento, pois não acreditam nem reconhecem o progresso da melhoria clínica.

Nessa direção, Kleinman 39 sugere que a equipe deve estimular, no próprio paciente, as fontes de conhecimento, técnicas e novas condições do tratamento que podem tornar o cuidado de si mesmo mais efetivo. Podemos inferir que essas mulheres não conhecem a dimensão do tratamento da queimadura e suas sequelas. No entanto, não basta dispor da tecnologia para o diagnóstico e a terapêutica, é fundamental abarcar a complexidade humana ${ }^{40}$. Reconhecemos que a Política Nacional de Humanização (PNH) 41 trouxe um avanço para o Sistema Único de Saúde (SUS) que vai além da valorização das dimensões subjetiva e social. Para o cuidado e a promoção da clínica ampliada focada nas abordagens convencionais, somente na doença, nossa pesquisa no Ceará constata que, na realidade, não há, ainda, uma prática clínica centrada na pessoa humana.
Cumpre salientar, ainda, que o trabalho de Mol 42 argumenta que o confronto entre a fragilidade do corpo, as limitações e o avanço tecnológico gera realidades múltiplas. Nossa pesquisa corrobora com a autora 42 . No mundo de significados das queimaduras, etnografamos as práticas e os eventos que fazem (enactment) a enfermidade ${ }^{42}$. A compreensão da enfermidade não se esgota na experiência individual e isolada, mas abrange, também, os significados sociais que variam entre grupos diferentes. Afirmamos que o estigma e a vergonha associados às sequelas das queimaduras são socioculturalmente construídos. O olhar julgador do outro é o que torna a cicatriz da epiderme uma "desgraça" - uma marca "MA" de Marcos - deixada maculada no corpo 11,12,15. Assim, a cicatriz absorve um juízo de valor moral. Kleinman 12 afirma que é melhor compreender o estigma como experiência moral 11,12, configurado dentro de um mundo local e particular - como, no nosso caso, numa unidade de queimados.

Conforme a narrativa de Eva, a violência doméstica gerou traumas, procurando o pronto atendimento, pois queimaduras são $20 \%$ dessas agressões ${ }^{37}$. Essa lesão por ato de violência é assunto complexo, e, na prática, muitos fatores interferem, sendo necessário considerar a subjetividade da vítima, as condições socioeconômicas, políticas e culturais 37,39 . O efeito dessa agressão resultou nessa mulher danos irreparáveis. Desencadeou não apenas uma urgência médica, mas sérios problemas físicos, psicológicos e financeiros para ela, para a sua família e para a sociedade.

Por conseguinte, estigma, violência pelos parceiros íntimos ampliam mais ainda a vulnerabilidade das mulheres 6,7 , descobrindo que os únicos valores que importam são aqueles que ela tem além da próxima ameaça. Segundo Minayo ${ }^{6}$, a violência conjugal é a extensão, para a esfera privada, de um domínio "machista" em prática na totalidade da sociedade.

Um aspecto intrigante da nossa exploração etnográfica é o caso da Tânia. Ela nos mostra até que ponto o desafio das sequelas permitiu realizar sua autonomia como mulher. Vem-nos confrontando com o modelo funcional ou relacional 40 simetricamente inverso frente às narrativas anteriores. Diante de uma ameaça de dor, desfiguração, perda de função e incapacidade grave, Tânia e a família reformulam a experiência do sofrimento dentro de seu mundo moral local 12 , refazendo significados, emoções e valores por meio de atividade religiosa e até estética. Mol 42 traz, em perspectiva, que as mudanças acontecem a partir da multiplicidade do cuidado, o qual extrapola o "capital - aparência”, quando permite 
que o sujeito participe diretamente pela escolha do seu tratamento ${ }^{42}$. Kleinman 39 também enfatiza o cuidado por meio da relação paciente, familiares e pessoal encarregado da terapêutica.

No caso de Tânia, a narrativa se desconecta fisicamente de um arcabouço teórico. Apesar de visões apocalípticas, o corpo dela se multiplica, adquire dinâmica entre exterioridade e interioridade, força na própria ausência física, ganha um inconsciente 32,33 . Portanto, saindo do aspecto físico e orgânico de constatação objetiva, percebe-se que a consciência, a atitude e o equilíbrio das emoções de Tânia dependem do grau de maestria do afeto maternal, do tipo de "ferramentas" disponíveis, da receptividade e da interação familiar. Talvez, por essa razão, como diz Barasch 43, para o caminho da cura, há toda uma gama de níveis energéticos, seja físico, emocional, mental ou ainda espiritual 43. Dentro de uma perspectiva cultural, ela se ajusta aos desafios da modernidade, descobre como ultrapassar os obstáculos impostos pela adversidade, buscando aquele espaço interior que é repleto da inteligência do universo, a energia vital 43 - a fonte da vida.

\section{Conclusão}

Este estudo antropológico acrescenta o conhecimento da experiência de mulheres que sofreram queimaduras. É uma verdadeira "experiência dos limites" da vida, desvelando possibilidades de superação da visão do corpo da Biomedicina. A experiência da enfermidade para essas mulheres é um sofrimento social, centrado na cronicidade, desmoralização, estigma e vergonha. Retrata situações vividas por pessoas fragilizadas, em detrimento à complexidade. A carga emocional, o desespero e a dor da epiderme danificada têm uma dimensão moral.

Os resultados evidenciam que a lógica do cuidado é um processo interativo, aberto, que exige que pacientes e profissionais estejam em sintonia, buscando sensibilidade e sabedoria com o ambiente. É preciso que os profissionais de saúde penetrem nas representações êmicas (de dentro para fora), compreendendo e encarando o sofrimento dos seus pacientes. Não negamos a melhoria com o tratamento médico. A vulnerabilidade provocada pela sequela da queimadura, entretanto, exige uma política de humanização do cuidado.

\section{Colaboradores}

C. N. Arruda, A. S. G. Braide e M. Nations participaram da elaboração do projeto, coleta de dados, análise dos resultados e redação do artigo.

\section{Agradecimentos}

A nossas informantes, à Dra. Arlene Michele Katz, do Departamento de Saúde Global e Medicina Social da Universidade de Harvard, pelo seu olhar crítico e construtivo. M. Nations agradece o apoio do CNPq (projeto no 307346/2011-0). Agradecemos a colaboração do grupo de pesquisa Cultura e Humanização do Cuidado, por contribuições e reflexões sobre a experiência do sofrimento. bustible por accidente" (alcohol) oculta la cruel realidad de la "carne cruda y tostada". La cicatriz es capaz de desfigurarlas y transformarlas "no-personas" empañar su reputación moral y generar rechazo social. En el nordeste brasileño, la vulnerabilidad social, causada por las secuelas de quemaduras requiere una política de cuidado humano. 


\section{Referências}

1. Struck JF. A crueldade por trás de crimes que assustam o país. http://wwwveja.abril.com.br/noticia/ brasil/a-crueldade-por-tras-de-crimes-que-assus tam-o-pais (acessado em 05/Mai/2013).

2. Waiselfisz JJ. Homicídio de mulheres no Brasil. Mapa da violência 2012. Caderno Complementar 1. http://www.mapadaviolencia.org.br/pdf2012/ MapaViolencia2012_atual_mulheres (acessado em 04/Fev/2014).

3. Rebhun LA. The heart is unknown country: love in the changing economy of Northeast Brazil. Palo Alto: Stanford University Press; 2002.

4. Caprara A, Rodrigues J. A relação assimétrica médico-paciente: repensando o vínculo terapêutico. Ciênc Saúde Coletiva 2004; 9:139-46.

5. Saffioti H. Gênero, patriarcado, violência. 2a Ed. São Paulo: Editora Fundação Perseu Abramo; 2007.

6. Minayo MCS. Laços perigosos entre machismo e violência. Ciênc Saúde Coletiva 2005; 10:18-34.

7. Faheina R. Assassinato de mulheres: números crescem no Cariri, Ceará. http://www.opovo.com.br/ opovo/ceara (acessado em 08/Fev/2013).

8. Arruda $\mathrm{CN}$. Inscrita no corpo, gravada na carne: experiência de ser queimada em mulheres nordestinas. [Dissertação de Mestrado]. Fortaleza: Universidade de Fortaleza; 2009.

9. Burke JF. The treatment of burn injury. Rev Bras Queimaduras 2003; 3:4-5.

10. Kleinman A, Yunxiang Y, Jun J, Lee S, Zhang E, Tianshu P, et al. Deep China: the moral life of the person (what anthropology and psychiatry tell us about China today). Berkeley: University of California Press; 2011.

11. Nations MK, Lira GV, Catrib AMF. Stigma, deforming metaphors and patients' moral experience of multibacillary leprosy in Sobral, Ceará State, Brazil. Cad Saúde Pública 2009; 25:1215-24.

12. Kleinman A. What really matters: living a moral life amidst uncertainty and danger. Oxford: Oxford University Press; 2006.

13. Meneghel SN, Hirakata VN. Femicídios: homicídios femininos no Brasil. Rev Saúde Pública 2011; 45:564-74.

14 Saving face [motion picture]. Denver: HBO Documentary Films; 2012.

15. Kleinman A. The illness narratives suffering, healing \& the human condition. New York: Basic Books; 1988.

16. Lima EMJR. Campanha de prevenção de queimaduras. In: Lima EMJR, Serra MCVF, organizadores. Tratado de queimaduras. São Paulo: Editora Atheneu; 2004. p. 407-20.

17. Instituto de Pesquisa Aplicada. Duas décadas de desigualdade e pobreza no Brasil medidas pela PNAD/IBGE no 159. http://www.ipea.gov.br/por tal/images/stories/PDFs/comunicado/131001_co municado159.pdf.(acessado em 07/Fev/2014).

18. World Health Organization. Facts about injuries: burn. http://www.who.int/mipfiles/2014/burns1. pdf (acessado em 30/Jan/2013).
19. Bernal C. Cidade extrapola seus limites. http:// adm.noolhar.com/servlet/opovo?event=ctdi_noti cia (acessado em 10/Out/2009).

20. Maia R. O preocupante quadro da desigualdade social em Fortaleza. http://www.opovo.com.br/ app/opovo/politica/2013/01/19/noticiasjornal politica (acessado em 10/Mai/2013).

21. Minayo MCS. O desafio do conhecimento: pesquisa qualitativa em saúde. São Paulo: Editora Hucitec/Rio de Janeiro: ABRASCO; 2000.

22. Spradley, JP. The ethnographic interview. New York: Holt, Rinehart and Winston; 1979.

23. Lira GV, Catrib AMF, Nations MK. A narrativa na pesquisa social em saúde: perspectiva e método. Rev Bras Promoç Saúde 2003; 16:59-66.

24. Iturra R. Trabalho de campo e observação participante em antropologia. In: Silva AS, Pinto JM, organizadores. Metodologia das ciências sociais. 10aㅡ Ed. Porto: Edições Afrontamento; 1999. p. 32-43.

25. Yin RK. Estudo de caso: planejamento e métodos. 2a. Ed. Porto Alegre: Bookman Editora; 2001.

26. Berry JW. Emics and etics: a symbiotic conception. Culture \& Psychology 1999; 5:165-71.

27. Mol A. The body multiple: ontology in medical practice, Durham/London: Duke University Press; 2002.

28. Bardin L. Análise de conteúdo. Lisboa: Edições 70; 2002.

29. Bibeau G, Corin EE. From submission to the text to interpretive violence. In: Bibeau G, Corin EE, editors. Beyond textuality: asceticism and violence in anthropological interpretation. Berlin: Mouton de Gruyter; 1995. p. 3-54.

30. Geertz C. A interpretação das culturas. Rio de Janeiro: LTC Editora; 1989.

31. Barbarena RA. A lente fotográfica enquanto crítica cultural: escritas no corpo em cicatriz, de Rosangela Rennó. Crítica Cultural 2009; 1:171-91. http:// www3.unisul.br/paginas/ensino/pos/linguagem/ crítica/0401/040111 (acessado em 17/Ago/2009).

32. Porter R, Vigarello G. Corpo, saúde e doença. In: Corbin A, Courtine JJ, Vigarello G, editores. A história do corpo. Rio de Janeiro: Editora Vozes; 2008. p. 441-86.

33. Courtine JJ. O corpo anormal: história e antropologia culturais da deformidade. In: Corbin A, Courtine JJ, Vigarello G, editores. A história do corpo. Rio de Janeiro: Editora Vozes; 2008. p. 253-340.

34. Anzieu D. O eu-pele. São Paulo: Casa do Psicólogo; 1988.

35. Montagu A. Tocar: o significado humano da pele. 9a Ed. São Paulo: Editora Summus; 1988.

36. Breton D. Adeus ao corpo, antropologia e sociedade. Campinas: Papirus; 2003.

37. Diniz NMF, Lopes RLM, Rodrigues AD, Freitas DS. Mulheres queimadas pelos maridos ou companheiros. Acta Paul Enferm 2007; 20:321-5. http://www. redalc.org/articulo.oa?id=307026614013 (acessado em 17/Set/2009).

38. Laplantine F. Antropologia da doença. 4a Ed. São Paulo: Editora WMF Martins Fontes; 2010. 
39. Kleimann A. Writing at the margin: discourse between anthropology and medicine. Berkeley: University of California Press; 1995.

40. Morin E. A inteligência da complexidade: epistemologia e pragmática. São Paulo: Editora Petrópolis; 2009.

41. Ministério da Saúde. Política Nacional de Humanização (PNH): documento base para gestores e trabalhadores do SUS. Brasília: Ministério da Saúde; 2005.
42. Mol A. The logic of care: Health and the problem of patient choice. London: Duke University Press; 2005.

43. Barasch MI. O caminho da cura: uma visão espiritual das doenças. Rio de Janeiro: Editora Nova Era; 1997.

Recebido em 09/Out/2013

Versão final reapresentada em 17/Fev/2014

Aprovado em 12/Mar/2014 